\title{
Enkele reflecties op toezicht in het Nederlands strafrechtelijk sanctiestelsel
}

\author{
Jeroen ten Voorde*
}

In 2018 vergaderde de Vereniging voor de vergelijkende studie van het recht van België en Nederland over vrijheidsbeperking en vrijheidsbeneming in het strafrechtelijk sanctierecht. Namens Nederland schreef F.W. Bleichrodt een kritisch preadvies (Bleichrodt 2018). De preadviseur richtte zijn pijlen niet slechts op de 'onoverzichtelijkheid van het sanctiestelsel' (vgl. Bleichrodt 2011), hij wees er ook op dat een 'zware wissel wordt getrokken op de proportionaliteit van de strafrechtelijke sanctie'. Hij tekent als bezwaar aan dat aan recente wetswijzigingen 'geen overkoepelende gedachtevorming ten grondslag [ligt] over de plaats van toezicht in het sanctiestelsel' en spreekt van een 'risico van cumulatie van toezicht', terwijl een algemeen kader node wordt gemist. Volgens Bleichrodt is de tijd rijp voor een 'herbezinning' op het Nederlands strafrechtelijk sanctiestelsel (Bleichrodt 2018, p. 188). De roep om herbezinning wordt gekoppeld aan de groei van het toezicht in het Nederlands strafrechtelijk sanctiestelsel. Toezicht is een 'wijdverbreid en complex fenomeen' (Boone 2018) dat in het Nederlands strafrechtelijk sanctiestelsel sterk aan belang heeft gewonnen (Van der Wolf \& Struijk 2014; Struijk 2018). Het toegenomen belang van toezicht nodigt uit tot verder onderzoek. In deze bijdrage reflecteer ik op een aantal thema's die in het wetenschappelijk onderzoek over toezicht naar voren zijn gekomen, maar nog nauwelijks door een meer filosofische bril zijn bekeken. Deze thema's houden verband met de persoon die onder toezicht is gesteld, de betekenis van toezicht voor het Nederlands strafrechtelijk sanctiestelsel en de doelen van toezicht binnen ons sanctiestelsel.

* Prof. dr. mr. J. ten Voorde is universitair hoofddocent straf(proces)recht aan de Universiteit Leiden en bijzonder hoogleraar strafrechtsfilosofie (leerstoel Leo Polak) aan de Rijksuniversiteit Groningen. 
Ten aanzien van het eerste thema is in de afgelopen jaren onderzoek gedaan naar de rechtspositie van de onder toezicht gestelde (Boone 2009), alsmede naar de wijze waarop deze personen het op hen uitgeoefende toezicht hebben ervaren (zie verwijzingen in Boone 2018). Mogelijke gevolgen van toezicht voor het huidige Nederlands strafrechtelijk sanctiestelsel, in het bijzonder het daarin gemaakte onderscheid tussen straf en maatregel, zijn onder andere door Struijk (2018) en Schuyt (2011) gesignaleerd. Ook naar de doelen van toezicht (en het daadwerkelijk bereiken daarvan) is onderzoek gedaan, terwijl in onderzoek naar straffen in de huidige democratische samenleving ook op de plaats van toezicht is gewezen (Van Oenen 2011, p. 60). Deze onderzoeken hebben ons inzicht in toezicht verrijkt. Wat echter lijkt te ontbreken is onder meer expliciete aandacht voor het mensbeeld dat in het kader van het in dit nummer centraal staande toezicht wordt gehanteerd en wat dat mensbeeld voor ons inzicht in toezicht kan betekenen. In onderzoek naar toezicht door instanties wordt veel aandacht gegeven aan de praktische uitdagingen van het uitoefenen van toezicht, minder aandacht gaat uit naar toezicht in relatie tot de (straf)doelen die door toezichthouders moeten worden bereikt. Welke doelen kunnen worden onderscheiden en wat betekenen die doelen voor toezicht? Ook verdient de betekenis van toezicht voor het tweesporenstelsel onze aandacht. Is het voor ons sanctiestelsel zo kenmerkende onderscheid tussen straf en maatregel nog wel te handhaven? Deze bijdrage beoogt niet meer te zijn dan een eerste reflectie op de onderwerpen die zojuist werden genoemd. Daarbij vertrek ik vanuit relevante parlementaire stukken over toezicht, om vervolgens - associatief - te reflecteren op deze stukken en daarin verwoorde keuzes. Wat niet volgt is een doorwrocht filosofisch betoog, onderbouwd met veel literatuur, maar wel enkele opmerkingen die kunnen worden gezien als aandachtspunt bij verder onderzoek.

\section{Toezicht en autonomie}

Toezicht wordt uitgeoefend op iemand. Wie is de persoon die onder toezicht is gesteld? In de literatuur is daaraan de laatste jaren veel aandacht geschonken. Het valt op dat tamelijk veel wetenschappelijk onderzoek gericht is op het leren kennen van sociale en neurowetenschappelijke kenmerken van de mens die met het strafrecht te maken 
krijgt (Den Bak e.a. 2017). Hier komt een mensbeeld naar voren van een persoon die slechts in beperkte mate verantwoordelijkheid kan dragen voor zijn handelen en wiens handelen vooral moet worden begrepen in het licht van sociale en cognitieve beperkingen. ${ }^{1}$ Tegelijkertijd opteren beleidsmakers en politici voor een mensbeeld waarin de gestrafte persoon verantwoordelijk wordt gehouden voor een succesvolle tenuitvoerlegging van de aan hem opgelegde sanctie (Van Ginneken 2018). ${ }^{2}$ Met betrekking tot toezicht wordt in de toelichting bij het wetsvoorstel straffen en beschermen opgemerkt dat de veroordeelde 'zelf de sleutel in handen [heeft] voor een geslaagde terugkeer in de maatschappij. Met zijn gedrag en inspanningen tijdens de detentieperiode moet de gedetineerde kunnen laten zien dat hij bereid is te investeren in zichzelf.' ${ }^{3}$ Tevens wordt gesproken van het tonen van inzet voor een succesvolle terugkeer in de samenleving. ${ }^{4}$ Autonomie (of eigen verantwoordelijkheid) wordt in de geciteerde parlementaire stukken op twee manieren uitgelegd. Ten eerste wordt autonomie beschouwd als iets dat van een persoon is. Ten tweede wordt autonomie opgevat als het kunnen maken van keuzes. We spreken van persoonlijke en keuzeautonomie.

Over autonomie is heel veel geschreven. Het voert te ver alle perspectieven de revue te laten passeren. Ik maak hier gebruik van het handzame overzicht dat de filosoof Sneddon (2013) schreef. Deze omschrijft persoonlijke autonomie als de overkoepelende notie van autonomie. Zij bestaat onder andere uit keuzeautonomie. Keuzeautonomie is de capaciteit om te kunnen kiezen en om op die keuzes te kunnen reflecteren. Autonoom is een keuze wanneer na reflectie dit de keuze is die iemand ook echt wil. Wanneer een veroordeelde in het kader van de tenuitvoerlegging van een straf of maatregel verklaart geen strafbare feiten meer te zullen plegen, is die keuze slechts autonoom wanneer hij ook na reflectie tot dezelfde conclusie komt. Keuzes die men - wanneer men de kans krijgt - weer terzijde schuift, zijn bijgevolg geen autonome keuzes.

Men kan zich afvragen of het in het kader van toezicht ertoe bewegen van veroordeelden om de autonome keuze te maken om geen straf-

1 Bijv. Koers \& Kansen. Whitepaper over de toekomst van de sanctie-uitvoering. Bijlage bij Kamerstukken I/ 2016/17, 24587, 689, p. 9.

2 Ook strafrechtswetenschappers benadrukken het belang van het autonome subject. Zie o.a. De Jong 2012.

3 Kamerstukken I/ 2018/19, 35122, 3, p. 6.

4 Kamerstukken I/ 2013/14, 33816, 3, p. 24. 
bare feiten meer te plegen een vorm van externe beïnvloeding is (manipulatie) die op gespannen voet staat met autonomie. Kun je willen wat je echt wilt als een ander vertelt wat je moet willen? Wanneer de extern beïnvloede keuzes integreren met de rest van een persoon, is autonomie volgens Sneddon nog steeds denkbaar (2013, p. 37 e.v.). Wanneer hij de keuze geen misdaad te plegen integreert in de rest van zijn 'zelf', is het een autonome keuze om voortaan zonder misdaad te leven. Beleid dat er niet op is gericht een leven zonder misdaad te laten internaliseren in een persoon, is er niet op gericht iemand met een beroep op zijn autonomie of eigen verantwoordelijkheid te laten kiezen voor een leven zonder misdaad. Het is beleid voor de korte termijn, voor de eerste, niet-doordachte, keuze. Het stimuleert mogelijk wel calculerend gedrag (vgl. Struijk 2018), maar daarmee is niet gezegd dat de veroordeelde de misdaad voortaan echt wil afzweren. Persoonlijke autonomie omvat ook het vermogen tot zelfkennis (Sneddon 2013, p. 49 e.v.). Zelfkennis komt neer op het vermogen controle over het eigen leven uit te oefenen. Daarbij gaat het om het hele leven, niet slechts een deel ervan, bijvoorbeeld het feit dat hij strafbare feiten pleegt. Hiervoor zagen we dat een veroordeelde moet investeren in zichzelf. Wat daarmee wordt bedoeld, is niet helemaal duidelijk. Onduidelijk is ook of het toezicht dat op een Nederlandse veroordeelde wordt uitgeoefend op zijn gehele persoon ziet. Soms houdt het toezicht slechts verband met het strafbare feit dat is gepleegd. Dat verband is soms sterk, maar wanneer we het toezicht in het kader van de gedragsbeïnvloedende en vrijheidsbeperkende maatregel in ogenschouw nemen (art. 38ab Wetboek van Strafrecht), dan is er wel een verbinding met het gepleegde strafbare feit te maken, al is zij niet heel erg sterk (Fokkens 2016). Ook in het wetsvoorstel straffen en beschermen wordt nadruk op de persoon gelegd en staat het strafbare feit waarvoor hij is veroordeeld meer op de achtergrond. ${ }^{5}$ Dat zou erop kunnen duiden dat het investeren in zichzelf betekent dat een persoon in zijn gehele persoon moet investeren.

Investeren in de persoon als geheel betekent dat hij niet alleen moet laten zien dat hij geen strafbare feiten meer zal plegen. Hij moet meer dan dat. Dat brengt ons bij het derde onderdeel van autonomie: zelfcreatie. Jezelf creëren is controle over je eigen identiteit krijgen en keuzes kunnen maken over jezelf (Sneddon 2013, p. 59). Het gaat er 
hier vooral om dat toezicht uitoefenen op een persoon die in zijn gehele persoon moet investeren de vraag oproept hoever dat toezicht eigenlijk reiken moet en mag. Met betrekking tot de reclassering wordt opgemerkt dat zij resocialiserende componenten moet verwerken in het toezicht (RSJ 2017, p. 15). Die houden veelal verband met het delict dat is begaan en waarvoor iemand is veroordeeld. Dat zou betekenen dat die trainingen de persoon helpen bij het investeren in een deel van zichzelf. We zien ook een persoonsgerichte aanpak vooropstaan, waarmee de gehele persoon lijkt te worden bedoeld. Daarvoor kunnen ook andere trainingen gewenst zijn dan die met het strafbare feit in verband staan. Indien dat de bedoeling is, dwalen we dan niet af van de strafrechtelijke titel op basis waarvan toezicht wordt uitgevoerd ${ }^{6}$ Is de inbreuk op de persoon dan niet te groot? Wordt dan aan autonomie gewerkt, of wordt zij juist tegengewerkt?

\section{Toezicht en het tweesporenstelsel}

Het tweesporenstelsel beschermt de burger tegen een vergeldende straf die ontkoppeld is van schuld en maakt tegelijkertijd het opleggen van een uit oogpunt van schuld disproportionele maar in het belang van preventie en beveiliging noodzakelijke sanctie mogelijk. Het onderscheid tussen straf en maatregel heeft in het bijzonder vanaf het einde van de negentiende eeuw vorm gekregen ten gevolge van een verfijning van het denken over strafdoelen en het plaatsen van preventie boven vergelding. Het onderscheid tussen straf en maatregel is in ons strafrechtelijk sanctiestelsel nog steeds 'leidend' (Bleichrodt \& Vegter 2016, p. 40). Het geformuleerde onderscheid tussen beide typen sancties neemt niet weg dat straf en maatregel naar elkaar toe zijn gegroeid. Dat hoeft het onderscheid op theoretisch niveau niet weg te nemen, tenzij er sprake is van een situatie die ook op theoretisch niveau ertoe moet leiden dat het onderscheid tussen straf en maatregel opnieuw moet worden doordacht. Geeft het toegenomen belang van toezicht aanleiding tot een doordenking van het tweesporenstelsel?

6 De worsteling met het toezicht op Volkert van der G. gedurende zijn voorwaardelijke invrijheidstelling maakt de actualiteit van deze vragen indringend duidelijk. Zie over de casus Van der G. Boone 2018. 
Het valt op dat er op het niveau van de voorwaarden waarop toezicht kan worden uitgeoefend weinig verschil bestaat tussen straffen en maatregelen. Dat hoeft nog niet zoveel te zeggen. Straffen kunnen ook preventie en beveiliging tot doel hebben. Het belangrijkste verschil tussen straffen en maatregelen is echter de nadruk die bij straf wordt gelegd op proportionaliteit en - via schuld - de relatie met het gepleegde strafbare feit. Dat zou met zich kunnen meebrengen dat toezicht aan tijd gebonden moet zijn, als de uitdrukking van proportionaliteit en de voorwaarden waarop de naleving wordt toegezien, verband houden met het strafbare feit waarvoor is gestraft. Bij maatregelen is die binding aan tijd en strafbaar feit hoegenaamd afwezig. Dat maakt dat 'tijdloos' toezicht in ieder geval denkbaar is.

De relativering van de verbinding tussen strafbaar feit en straf op het niveau van de voorwaarden waarop toezicht wordt uitgeoefend, zou op zichzelf ook kunnen worden gerelativeerd. Dat kan op twee manieren. Ten eerste heeft vergelding als strafdoel misschien lang niet zo'n prominente status als in de discussie over het tweesporenstelsel wel wordt verondersteld. Ze wordt als strafdoel wel opgevoerd (in de vorm van leedtoevoeging aan de dader en herstel van door hem veroorzaakt leed), maar de nadruk ligt vooral op het strafdoel voorkomen van herhaling. ${ }^{7}$ Als ook straffen vooral met dat doel worden opgelegd, is het verschil met maatregelen gerelativeerd, waardoor het niet zo vreemd is dat het toezicht op het naleven van voorwaarden onderling weinig verschil vertoont. De vraag zou dan opkomen waarom - als toezicht op naleving van voorwaarden met het oog op het voorkomen van herhaling van strafbare feiten zo belangrijk is - het bestaande sanctiestelsel wordt gehandhaafd.

Ten tweede zou kunnen worden beweerd dat het beeld dat we bij vergelding hebben niet juist is. Vergelding koppelen we nu aan het strafbare feit dat is begaan. Opvallend aan het discours over toezicht is dat daarbij soms het verleden relevant kan zijn, namelijk in het kader van verlenging van de proeftijd. Verlenging daarvan (en dus van het toezicht) wordt namelijk gerechtvaardigd als adequate reactie op 'problemen die zich bij de veroordeelde bij het naleven van de aan de VI verbonden voorwaarden' hebben voorgedaan. ${ }^{8}$ Verlengd toezicht dus als vergelding voor het niet naleven van voorwaarden. Vergelding wordt hier nog beschouwd als reactie op gepleegd 'onrecht'. Van Stokkom 
meent dat we ons bij vergelding op het verleden én de toekomst moeten oriënteren. In een prikkelend artikel, prikkelend mede omdat veel auteurs er met reden van uitgaan dat bij vergelding het verleden centraal staat (Ten Voorde 2015), omschrijft Van Stokkom een vergeldende straf als 'een opzettelijke inbreuk op vrijheden en rechten van de schuldige, die deprivatie en verplichtingen met zich meebrengt' (2016, p. 796). Hij koppelt de verplichtingen primair aan herstel voor slachtoffers en stelt zich hiermee in een traditie die inmiddels ook onze wetgever lijkt aan te spreken. Die verbindt straffen ook steeds meer met de belangen van slachtoffers, al is daarmee niet gezegd dat de wetgever het perspectief van Van Stokkom helemaal omarmt. ${ }^{9}$ Verplichtingen hebben volgens Van Stokkom ook met de dader zelf te maken: 'Het komt erop aan dat de verplichting [de veroordeelde] aanspoort tot het nemen van verantwoordelijkheid' (2016, p. 803). Verantwoordelijkheid nemen hoeft niet beperkt te zijn tot herstel van het leed dat slachtoffers is aangedaan, zij kan meer algemeen ook betrekking hebben op het treffen van maatregelen om te voorkomen dat iemand opnieuw strafbare feiten begaat. Daarop toezien is niet alleen nodig om te bezien of verplichtingen worden nagekomen. Is niet denkbaar dat met toezicht ook enige deprivatie wordt bereikt? En als dat het geval is, wat moeten we daaruit afleiden met betrekking tot het onderscheid tussen straf en maatregel in ons sanctiestelsel? De omschrijving van straf door Van Stokkom roept de vraag op of hij nog een verschil ziet tussen straf en maatregel. De term schuldige kan misleidend zijn, omdat hij niet gelijkstaat aan een persoon die een verwijt wordt gemaakt. Het kan ook gaan om een persoon die een strafbaar feit heeft begaan. Ook de persoon die ter beschikking is gesteld, is dan schuldige. Onduidelijk is ook of deprivatie en het nemen van verantwoordelijkheid onder het verband van het opzet staan, of dat meebrengen een kleurloos begrip is en slechts een causaal verband veronderstelt. Van Stokkom is ook op dit punt niet zonder meer duidelijk (2016, p. 802). Indien slechts een causaal verband wordt verondersteld, vallen maatregelen ook onder de definitie, waardoor het onderscheid tussen straf en maatregel irrelevant is geworden. Is dat wenselijk? Het antwoord daarop hangt af van het antwoord op meerdere vragen, waaronder: hoe belangrijk is schuld (in de zin van verwijtbaarheid) voor het onderscheid tussen straf en maatregel en voor het 
bepalen van straf; hoe belangrijk is proportionaliteit in het sanctiestelsel; en - bij een zeker belang - hoe garanderen we proportionaliteit? Van Stokkom introduceert het begrip 'publieke redelijkheid' en stelt dat de 'verplichtingen' die daders 'op zich nemen' in overeenstemming moeten zijn met 'de ernst van de inbreuk' (2016, p. 797). Met betrekking tot toezicht zou kunnen worden beweerd dat toezicht tijdens de tenuitvoerlegging van een straf aan tijd en intensiteit gebonden moet zijn. Hoe deze moeten worden bepaald, is onduidelijk wanneer niet alleen het verleden, maar ook de toekomst relevant is voor vergelding. Een andere vraag is of publieke redelijkheid ook relevant moet zijn voor het toezicht in het kader van het opleggen van maatregelen, en welke gezichtspunten daarbij dan in acht genomen moeten worden.

\section{Doelgerichtheid van toezicht}

Strafrechtelijk toezicht ziet op naleving van voorwaarden die kunnen worden opgelegd. Die worden om een bepaalde reden of met een bepaald doel opgelegd. Het formuleren van doelen betekent dat het behalen daarvan wordt nagestreefd. In beleidsdocumenten en parlementaire stukken waarin naar toezicht wordt verwezen, wordt verbinding gelegd met het terugdringen van recidive. Dat is volgens de minister voor Rechtsbescherming op drie manieren mogelijk: door afschrikking, incapacitatie en resocialisatie. Deze manieren worden kortweg omschreven als niet durven recidiveren, niet kunnen recidiveren en niet willen recidiveren. ${ }^{10}$ Hierop wordt toezicht uitgeoefend. Als we deze manieren van terugdringing van recidive en toezicht met elkaar in verband brengen, ontstaat het volgende beeld.

Toezicht op incapacitatie lijkt het meest eenvoudig, door erop toe te zien dat een persoon zich niet onrechtmatig aan zijn insluiting onttrekt. ${ }^{11}$ Toezicht in het kader van afschrikking en resocialisatie moet meer omvatten. Bij afschrikking zal het toezicht zo moeten zijn ingericht dat de persoon die onder toezicht is gesteld dat zo onprettig vindt dat hij het niet meer in zijn hoofd haalt om opnieuw in de fout te gaan. Met betrekking tot resocialisatie staan centraal 'evidence-based' 
interventies die op maat van de veroordeelde zijn gesneden. Toezicht bestaat dan uit effectieve hulp en steun.

Het voorgaande wijst uit dat hoewel er tussen toezicht en het terugdringen van recidive een relatie wordt onderkend, dat op zichzelf nog niet zoveel zegt. Het hangt van de wijze waarop men recidive wil terugdringen af hoe men het toezicht inricht. Over het toezicht kan nog meer worden gezegd.

Toezicht vindt plaats in het hier en nu. Bij afschrikking en resocialisatie geldt dat het toezicht op de toekomst is gericht. Incapacitatie betekent hier niet meer dan dat tijdens insluiting geen strafbare feiten worden gepleegd. Of door insluiting recidive na insluiting wordt voorkomen, hoeft niet het doel van insluiting te zijn. Toezicht komt neer op controle op ingeslotenheid. Bij afschrikking gaat het erom dat ook na ommekomst van de straf geen strafbare feiten meer zullen worden gepleegd. Hier wordt benadrukt dat de straf, inclusief het daarin opgelegde toezicht, voor de veroordeelde een groter nadeel vormt dan het voordeel dat hij met het begaan van strafbare feiten heeft behaald. Toezicht is bij zowel incapacitatie als afschrikking een inspanningsverplichting, die overigens niet hetzelfde is. Bij afschrikking geldt ook een resultaatsverplichting: het toezicht moet de veroordeelde ertoe hebben gebracht dat hij na ommekomst van de sanctie geen strafbare feiten meer zal begaan. Een resultaatsverplichting zien we bij toezicht op incapacitatie slechts met betrekking tot de insluiting zelf. Ook bij toezicht in het kader van resocialisatie gelden een inspannings- en resultaatsverplichting. De voorwaarden waarop toezicht wordt uitgeoefend, hebben tot doel dat de veroordeelde voortaan afziet van het begaan van strafbare feiten. Anders dan bij afschrikking gaat het bij resocialisatie niet alleen om een rationele afweging van de voordelen van het begaan van strafbare feiten en de nadelen van het ondergaan van een sanctie; bij resocialisatie moet toezicht leiden tot heropvoeding. Zij kan in termen van kosten-baten zijn vormgegeven, ze kan ook (andere) idealen op het oog hebben.

De minister gaf met zijn opsomming van manieren van recidivevermindering geen rangorde aan. Dat beoogde hij ook niet. Hij beoogde zelfs niet te stellen dat recidivevermindering het enige te bereiken doel is. ${ }^{12}$ Wordt echter niet te veel verwacht van het toezicht en van de instanties die belast zijn met het uitvoeren van toezicht? Een andere 
vraag is of met de veelheid van te bereiken doelen, elk daarvan kan worden bereikt. Die vraag veronderstelt dat de verschillende doelen van elkaar afwijken. De doelen hebben met elkaar gemeen dat zij telkens gaan over het beheersen van risico's. Deze risico's, vooral het risico op herhaling, worden meetbaar geacht. Er wordt zelfs grote waarde gehecht aan te meten risico's, omdat die consequenties kunnen hebben voor het verlengen (en aanpassen) van het uitgeoefende toezicht. De Wetenschappelijke Raad voor het Regeringsbeleid (WRR) meent dat helderheid over (kwantitatieve en kwalitatieve) effecten van toezicht 'een belangrijke bijdrage lever[t] aan de publieke verantwoording over de opbrengsten en maatschappelijke meerwaarde' van toezicht. Volgens de WRR kunnen toezichthouders dan 'ook beter laten zien welke politieke en maatschappelijke verwachtingen van het toezicht wel of niet realistisch zijn' (WRR 2013, p. 64). De wens lijkt hier de vader van de gedachte. De vraag zou ook moeten zijn welke verwachtingen gewekt mogen worden.

Toezicht vindt in de regel gedurende een bepaalde tijd plaats. Die tijdsbegrenzing is gerelativeerd (verlenging van proeftijden) en is soms zelfs geheel verdwenen (denk aan de vrijheidsbeperkende en gedragsbeïnvloedende maatregel). Een en ander wordt onderbouwd met een beroep op het recidiverisico en maatschappelijke veiligheid. Alleen tijdens toezicht kunnen zij worden gesignaleerd, teruggedrongen of ingeperkt. ${ }^{13}$ Wordt hier een nieuw doel van toezicht geformuleerd dat gelijkenissen vertoont met incapacitatie (vgl. Struijk 2014; Duker \& Malsch 2012)? Gelijk incapacitatie is het doel daarvan niet op de toekomst gericht, maar op het hier en nu. Indien met toezicht slechts het reguleren van gedrag in het heden wordt bewerkstelligd, wordt de toekomst irrelevant. Dat kan consequenties hebben voor de inrichting van het toezicht en de mogelijkheden om in de toekomst een toezichtvrij bestaan te leiden. Wanneer bijvoorbeeld niet wordt gewerkt aan resocialisatie, is denkbaar dat gedragsverandering niet wordt bereikt en het risico voor slachtoffers en gemeenschap onverminderd aanwezig blijft, als gevolg waarvan het verminderen of zelfs opheffen van het toezicht lastig te bereiken valt. Onder toezicht staan betekent dan een manier van leven, terwijl het bestaansrecht van toezicht verandert: van het bereiken van een toekomstig doel krijgt toezicht een op zich- 
zelf gericht doel. Of dat doel aanvaardbaar is, verdient nader onderzoek.

\section{Afsluiting}

Deze bijdrage beoogde een eerste, tamelijk associatieve, reflectie te geven op enkele onderwerpen die met het fenomeen toezicht in verband kunnen worden gebracht. Drie onderwerpen passeerden de revue: de relatie met autonomie, de mogelijke betekenis van toezicht voor het tweesporenstelsel en een reflectie op enkele strafdoelen en de wijze waarop daarop toezicht kan worden uitgeoefend. Het voorgaande wijst er niet alleen op dat ten aanzien van de drie onderwerpen afzonderlijk allerlei vragen opkomen die in verder onderzoek over toezicht kunnen worden geadresseerd. Wat ook opvalt is dat er tussen de verschillende onderwerpen raakvlakken zijn. In het bijzonder komt de vraag op hoe het mensbeeld van het autonome subject zich verhoudt tot de doelen die in het kader van toezicht worden gesteld alsmede de neiging om toezicht als doel in zichzelf te beschouwen. Hoewel het realiseren van autonomie in een setting waarop toezicht wordt uitgeoefend niet onmogelijk is, lijkt er een zekere spanning te ontstaan wanneer toezicht een doel in zichzelf wordt. Bij toezicht als doel in zichzelf kunnen diverse kanttekeningen worden geplaatst, waarvan een belangrijke is dat irrelevant wordt of er met toezicht iets wordt bereikt. De status quo dat er toezicht wordt uitgeoefend, lijkt belangrijker dan dat er tijdens het uitoefenen van toezicht gewerkt wordt aan een bepaald doel, zoals het voorkomen van recidive. Hoewel hiervan in algemene zin wellicht geen sprake is, valt op dat met betrekking tot toezicht de laatste jaren vooral in tijd onbepaald toezicht mogelijk is gemaakt en ten minste de schijn wordt gewekt dat de status quo van toezicht belangrijker is dan de toekomst van de persoon die onder toezicht is gesteld. Opvallend in dit verband is dat toezicht inmiddels ook naar het verleden verwijst, alsof voor het bereiken van een status quo van toezicht zich iets in het verleden moet hebben afgespeeld dat dergelijk toezicht rechtvaardigt. Er lijkt aldus een verbinding te worden gelegd tussen vergelding en toezicht. Die verbinding, die hier werd gesignaleerd, maar waarnaar nader onderzoek zal moeten worden verricht, roept de vraag op naar de proportionaliteit van toezicht en de determinanten van proportionaliteit, als- 
mede de plaats van toezicht binnen het tweesporenstelsel en - van groter gewicht - de toekomstbestendigheid daarvan.

\section{Literatuur}

\section{Den Bak e.a. 2017}

R.R. den Bak e.a., Psychosociale criminogene factoren en neurobiologische kenmerken van mannelijke gedetineerden in Nederland, Den Haag: WODC 2017.

\section{Bleichrodt 2011}

F.W. Bleichrodt, 'Beperking van bewegingsvrijheid en beïnvloeding van gedrag in het Nederlands straf- en strafprocesrecht', in: Gedragsverboden en vrijheidsbeperkingen (Preadviezen voor de Nederlands-Vlaamse Vereniging voor Strafrecht 2011), Nijmegen: Wolf Legal Publishers 2011, p. 3-62.

\section{Bleichrodt 2018}

F.W. Bleichrodt, 'Vrijheidsbeperking en vrijheidsbeneming in het Nederlands strafrechtelijk sanctierecht', in: Preadviezen 2018 (Vereniging voor de vergelijkende studie van het recht van België en Nederland), Den Haag: Boom juridisch 2018, p. 153-188.

\section{Bleichrodt \& Vegter 2016}

E. Bleichrodt \& P.C. Vegter, Sanctierecht, Deventer: Wolters Kluwer 2016.

\section{Boone 2009}

M. Boone, 'Grenzen aan toezicht. Minimumwaarborgen voor de uitvoering van bijzondere voorwaarden', Proces 2009, p. 326-340.

\section{Boone 2018}

M. Boone, Paradoxen van toezicht. Straffen in het hart van de samenleving (oratie Leiden), 28 september 2018.

\section{Duker \& Malsch 2012}

M. Duker \& M. Malsch, “"Incapacitation”: Trends and new perspectives', in: M. Malsch \& M. Duker (red.), Incapacitation: Trends and new perspectives, Londen/New York: Routledge 2012, p. 237-251.

\section{Fokkens 2016}

J.W. Fokkens, 'De ontwikkeling van de vrijheidsbenemende sancties de laatste vijfentwintig jaar', Sancties 2016, afl. 1, p. 21-29.

\section{Van Ginneken 2018}

E.F.J.C. van Ginneken, 'Zelfredzaamheid in detentie: kritische kanttekeningen bij het systeem van promoveren en degraderen', Proces 2018, p. 113-129. 


\section{De Jong 2012}

F. de Jong, Straf, schuld en vrijheid. Pijlers van ons strafrecht, Amsterdam: Sjibbolet 2012.

\section{Van Oenen 2011}

G. van Oenen, 'Democratie en straf na de maakbare samenleving', Justitiële verkenningen 2011, afl. 8, p. 48-61.

\section{RSJ 2017}

Raad voor Strafrechtstoepassing en Jeugdbescherming, Reclassering in een veranderende omgeving. Implicaties van Visie op strafrechtelijke sanctietoepassing voor het reclasseringswerk, Den Haag 30 mei 2017.

\section{Schuyt 2011}

P.M. Schuyt, 'Persoonsgericht straffen: de voorwaardelijke veroordeling “nieuwe stijl”', Sancties 2011, p. 169-180.

\section{Sneddon 2013}

A. Sneddon, Autonomy, Londen/ New Delhi/New York/Sidney: Bloomsbury 2013.

\section{Van Stokkom 2016}

B. van Stokkom, 'Fatsoenlijk vergelden', Tijdschrift voor Filosofie 2016, p. 777-806.

\section{Struijk 2014}

S. Struijk, 'En nog meer en langduriger toezicht: de overheid als Rupsje Nooitgenoeg', Sancties 2014, afl. 3, p. 137-142.

\section{Struijk 2018}

S. Struijk, 'Vrijheidsbeperking na detentie: in hoeverre zet de rechter de achterdeur open?', Sancties 2018, af. 6, p. 65

\section{Ten Voorde 2015}

J. ten Voorde, Recht tot straffen, Amsterdam: Amsterdam University Press 2015.

\section{Van der Wolf \& Struijk 2014}

M.J.F. van der Wolf \& S. Struijk, '(Levens)lang toezicht als zelfstandige maatregel: wordt nu echt de Rubicon overgestoken?', Sancties 2014, afl. 6, p. 368-378.

\section{WRR 2013}

Wetenschappelijke Raad voor het Regeringsbeleid, Toezien op publieke belangen. Naar een verruimd perspectief op rijktoezicht (WRR-rapport 89), Amsterdam: Amsterdam University Press 2013. 